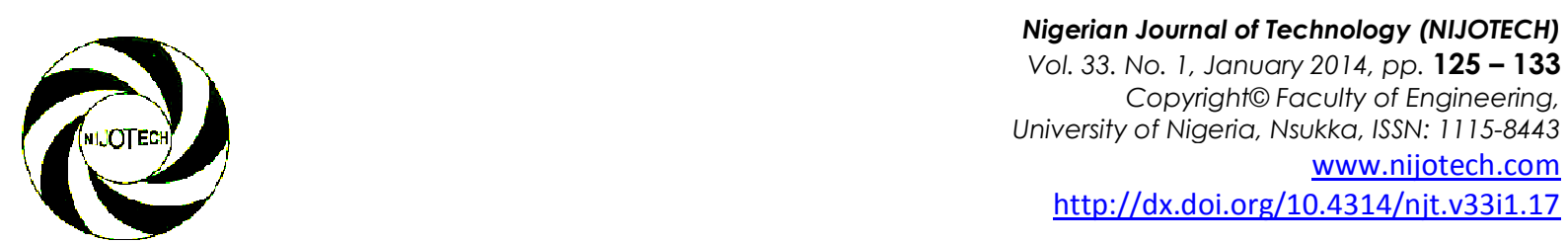

\title{
THE USE OF OPTO-DIGITAL MICROSCOPE FOR ANALYSIS OF PFA-BASED ABRASIVE TOOLS WITH SURFACE MICRO-DISCONTINUITIES
}

\author{
W. Kapłonek ${ }^{1}$, K. Nadolny ${ }^{2, *}$, S. Hloch ${ }^{3}$ \\ ${ }^{1}$ Subject Group of Metrology and Quality, KosZalin University of TeChNology, POLAND \\ ${ }^{2}$ Department of Production EngineEring, Koszalin University of TeChnology, POLAND \\ ${ }^{3}$ Department of Manufacturing Management, TeChNicAl University of KoŠice, SLOVAKIA \\ E-mail addresses: ${ }^{1}$ wojciech.kaplonek@tu.koszalin.pl, ${ }^{2}$ krzysztof.nadolny@tu.koszalin.pl \\ 3sergej.hloch@tuke.sk
}

\begin{abstract}
This paper presents the results of study using a modern opto-digital microscopic technique to observe, measure and analyses the active surface of ceramic grinding wheels made from pink fused alumina grains

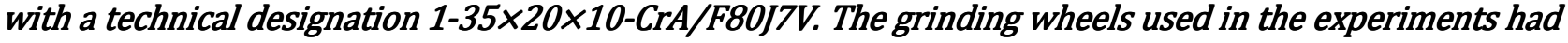
special active surface micro-discontinuities in a form of grooves from 0.5 to $1.5 \mathrm{~mm}$ deep, shaped deliberately using abrasive water-jet technology. The measurements of these characteristic elements were made using an advanced opto-digital microscope DSX500 by Olympus, equipped with the dedicated software STREAM Motion Desktop 1.8. This equipment made it possible to perform basic geometric analyses of the acquired grinding wheel surface images. They were carried out particularly in relation to some of the characteristic elements of structure of the grinding wheel such as micro-discontinuities, PFA abrasive grains, free intergranular spaces. Positive results from these tests confirmed the possible application of this microscopic technique within broadly defined diagnostics of abrasive tools.
\end{abstract}

Keywords. Opto-digital microscopy, Pink-Fused Alumina, Grinding wheel, Surface micro-discontiniuities.

\section{Introduction}

In modern production industries, especially within the fields of aeronautics, automotives and machinery, the increased efficiency of automated material removal processing is of the utmost importance [1]. Modern variations of grinding according to Chen et al. [2], Stephenson et al. [3], Shimizu et al. [4] as well as Odior and Oyawale [5], guarantee the acquisition of favorable machining effects and contribute to the maintenance of the proper exploitation parameters for shaped surfaces. A wide range of abrasive tools are used in many of these machining techniques, which include: different types of segments and lapping stones, as well as grinding wheels.

As such abrasive tools are at work, their active surface is often worn out, or a number of defects occurs. As far as grinding wheels are concerned, the occurrence of such phenomena as blunting abrasive grain apexes, cracking ceramic bond bridges and smearing of free intergranular spaces with grinding products (mostly with the machined material chips), result in errors in their shape or excessive temperature increase in the zone of contact between the tool and the machined material. As a consequence the workpiece surface layer quality deteriorates, and in some cases grinding defects, such as burns or micro fractures, appear. These effects were described in detail by Jackson and Davim [7], Marinescu et al. [8], Klocke [9], Xu et al. [10] as well as Jackson and Mills [11].

The undesired results brought about by the aforementioned phenomena can be prevented by applying properly directed diagnostics. In the case of abrasive tools a growth in the interest of optical methods, especially those that make use of various microscopic techniques, has been observed for a number of years now [12-14]. In this study, a modern form of light microscopy, known as opto-digital microscopy is presented. It 
is a relatively new observation-measurement technique whose characteristics are presented in Section 1.1. Moreover, the possibilities offered by the modern opto-digital microscope DSX500 by Olympus, in relation to analysis of the surface of ceramic grinding wheels with shaped microdiscontinuities, is also described by Nadolny [15]. A detailed description of the applied tool and the results from the experimental investigations carried out are also presented.

\subsection{Genesis and general characteristics of opto- digital microscopy technique}

The introduction of widely available photoelectric elements, such as the ChargeCoupled Device (CCD), onto the consumer market in the 1980s, resulted in the exceptionally dynamic development of a number of branches of science and technology which utilised imaging. The traditional way of acquiring a microscopic image on photographic film was basically abandoned for the sake of images acquired with digital cameras or camcorders. The combination of a simple optical system with the possibility of digital image acquisition and the ability to transfer acquired images to a computer, were first used in an instrument presented in the mid 1980s by Hirox (Japan) company. The instrument, initially called a video microscope and described by Inoué $[16,17]$ and Jarvis [18], turned out to be extremely useful. In a slightly modified form, as a hand-held video microscope system, it became standard equipment of the Japanese police in 1986, for example. It was also introduced onto the US consumer market later that year.

The development of video microscopy in the 1970s described by Inoué [19], Sluder and Wolf [20] as well as Wayne [21], as an observationmeasurement technique using digital imaging, led to the creation of its modern variant, called digital [22], or opto-digital, microscopy [23]. In this technique a new optical systems were used (aberration-free optics, telecentric lenses) and integrated with the detecting systems (matrix detectors of either a CCD or Complementary Metal-Oxide-Semiconductor (CMOS) type). As with video microscopy implementation of these elements allowed for transmission of the digital signal directly onto the monitor screen, which resulted in complete elimination of the possibility to observe the image through an eyepiece (the classical eyepiece was omitted in later models).
The image transmitted onto the monitor can not only be observed but also processed and analyzed. This has been made possible through the creation of dedicated computer software, which also allows for (in more advanced variants) the controlling of particular elements of the instrument, e.g. column movement through the $z$ axis, or the incorporation of a motorized stage through the $x$-y axes $[19,24]$.

A characteristic feature of opto-digital microscopes is their architecture. The majority of recent technical solutions have been based around the incorporation of a mounted (often motorized) measurement stage and a mobile optical head. The head may be calibrated for observation at an elevation angle (depending on the instrument type) ranging from $0^{\circ}$ to $90^{\circ}$ (for tilting to the right and to the left). Other characteristic elements, common for opto-digital microscopes are:

- a stationary computer station with dedicated software,

- an Liquid-Crystal Display (LCD) monitor (15" 23 ", sometimes also with a touch screen),

- a steering console (or joystick) with functional handwheels.

The opto-digital microscopy technique is developing dynamically, which can be observed by the analysis, among others, of the large number of commercial solutions currently available in the market. A number of companies from the microscopic industry such as Caltex Scientific, Celestron, Hirox, Keyence, Leica, Olympus and Sony offer such types of microscope.

\section{Material and Method}

\subsection{The main goals of the experimental investigations}

The main goal of the the experiments carried out was to analyze the possibility of applying optodigital microscopy in the measurement of microdiscontinuities of the grinding wheel active surface (GWAS). In practice this goal boiled down to determining the observation-measurement possibilities of the applied tool (opto-digital microscope DSX500 by Olympus) and to comparing the obtained measurement results with the results registered with the referential instrument (3D laser microscope LEXT OLS4000 by Olympus). The research works were carried out in accordance with the plan outlined below, which included four steps: 
Step 1: Choosing the samples for experimental investigations.

Step 2: Shaping the discontinuities on the GWAS. Step 3: Acquisition of micrographs of the GWAS.

Step 4: Analysis and interpretation of micrographs of the GWAS.

\subsection{Choosing the samples for the experimental investigations}

A set of 2 samples in the form of small-sized ceramic grinding wheels with shaped microdiscontinuities of a technical designation 1-35x $20 \times 10-$ CrA/F80J7V, were selected for the tests. The grinding wheels were made from Pink Fused Alumina (PFA) abrasive grains and glasscrystalline bond. They were marked with numbers 7 and 12 respectively. The general characteristics of the applied abrasive are presented in Table 1, while the features of the ceramic grinding wheels used in the measurements are depicted in Table 2 .

\subsection{Shaping the discontinuities on the GWAS}

In order to obtain surface micro-discontinuities, the examined samples underwent the hydro- jetting process. For this purpose the automated setup for abrasive water-jet cutting, equipped with adjustable precise cutting table WJ 3020b12 by PTV (Czech Republic) and dual intensifier pump 9XD55 by Flow System (USA), was used. Setup was installed and operated in DLC Ltd., (Prešov, Slovakia).

Three micro-discontinuities in the form of grooves were shaped on the active surface of each of the samples. The groove shaping was performed using an abrasive water-jet and an abrasive known commercially as Indian Garnet, and produced by Opta Minerals Inc. (Canada). The applied depth of the water-jet entrance into the material was $0.5 \mathrm{~mm}$ for the first groove (I). In the case of further working passes the depth was increased by $0.5 \mathrm{~mm}$, obtaining: $1.0 \mathrm{~mm}$ and $1.5 \mathrm{~mm}$, respectively for discontinuities Nos. II and III. The machining time was constant, i.e. $5 \mathrm{~s}$. The conditions and parameters for the process of shaping surface micro-discontinuities with an abrasive-water jet are presented in Table 3.

Table 1: General characteristics of pink fused alumina (PFA) abrasive grains

\begin{tabular}{ll}
\hline General name & Pink Fused Alumina \\
\hline Synonyms & Chromium (Pink) Fused Alumina, Pink Fused Aluminum Oxide, \\
Chemical name & Pink FA, Alodur Pink, CrA \\
Basic minerals & Chromium Fused Aluminum Oxide \\
Chemical composition and & $\alpha-\mathrm{Al}_{2} \mathrm{O}_{3}$ \\
percentage of elements & $\mathrm{Al}_{2} \mathrm{O}_{3}(99.52 \%), \mathrm{Fe}_{2} \mathrm{O}_{3}(0.05 \%), \mathrm{Na}_{2} \mathrm{O}(0.18 \%), \mathrm{Cr}_{2} \mathrm{O}_{3}(0.25 \%)$ \\
Crystal size $(\mu \mathrm{m})$ & $600-1400$ \\
Grain sizes & $\mathrm{F} 80^{* *}$ \\
Melting Point & $2050^{\circ} \mathrm{C}$ \\
True density $\left(\mathrm{g} / \mathrm{cm}^{3}\right)$ & $\geq 3.90$ \\
Bulk density $\left(\mathrm{g} / \mathrm{cm}^{2}\right)$ & $1.5-1.95$ \\
Knoop hardness $\left(\mathrm{Kg} / \mathrm{mm}^{2}\right)$ & $2200-2300$ \\
\hline
\end{tabular}

${ }^{*}$ Chemical composition for low chromium grains, ${ }^{*}$ according to FEPA 42-1:2006, ANSI B74.12 and ISO 8486-1:1996 standards

Table 2: General characteristics of grinding wheels used in the experiments

\begin{tabular}{ll}
\hline Technical designation & $1-35 \times 20 \times 10$-CrA/F80J7V \\
\hline Grinding wheel type & $1-$ flat grinding wheel \\
Dimensions & External diameter $35 \mathrm{~mm}$; Height $20 \mathrm{~mm}$; Internal diameter $10 \mathrm{~mm}$ \\
Abrasive grain type & Pink Fused Alumina (CrA) \\
Abrasive grain fracture & 80 \\
Hardness class & $\mathrm{J}$ \\
Structure No. & 7 \\
Volume of grains & $48 \%$ \\
Volume of bond & $10 \%$ \\
Volume of pores & $42 \%$ \\
Bond & Vitrified (amorphous glass bond) \\
Modifications & Micro-discontinuities shaped on the grinding wheel active surface \\
\hline
\end{tabular}




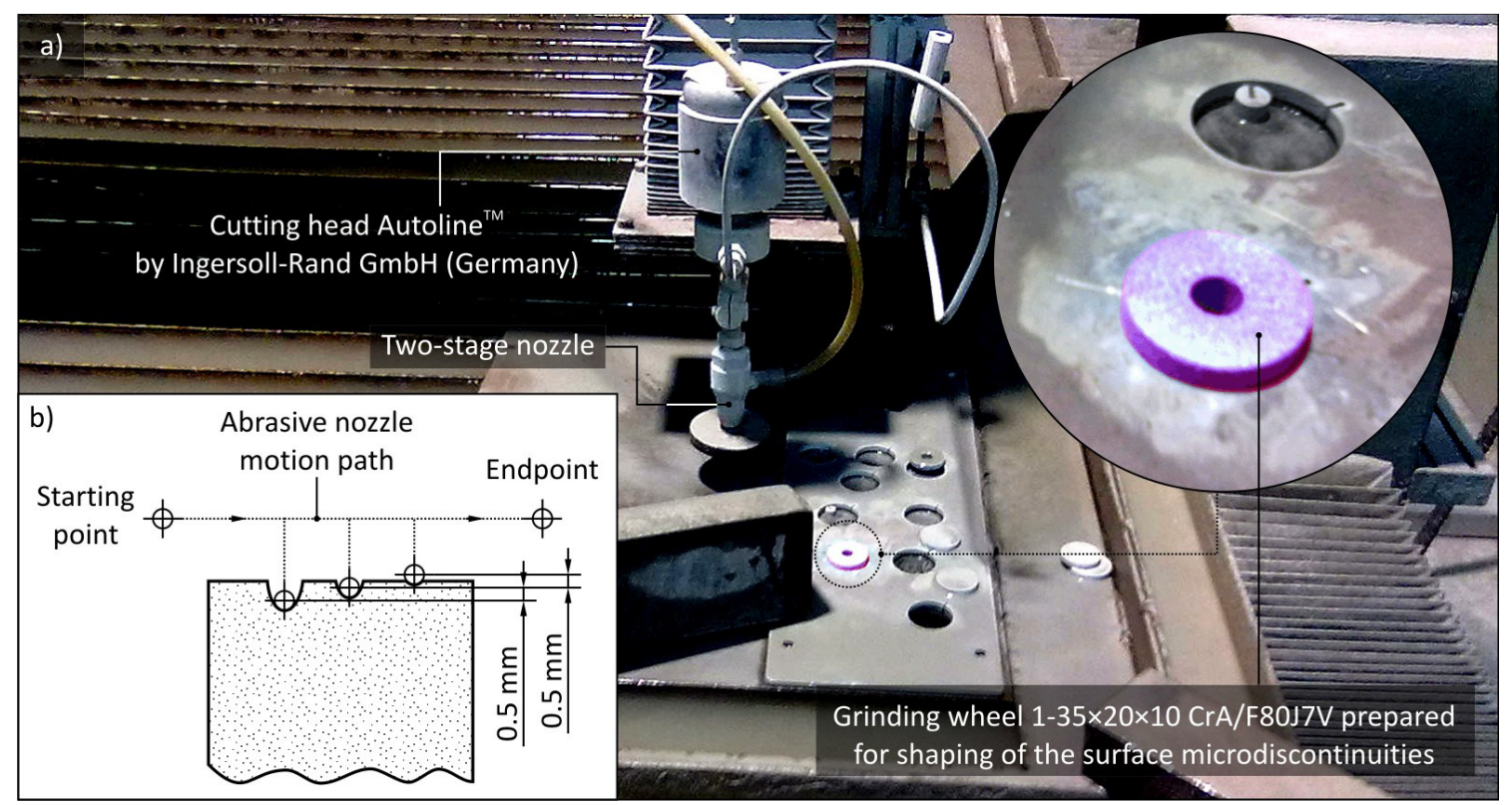

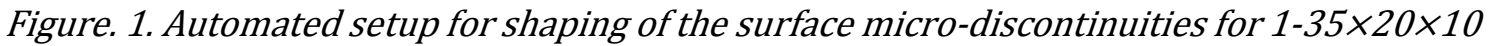
CrA/F80J7V grinding wheels

\subsection{Acquisition of micrographs of the GWAS}

Images of surfaces of all samples used in the tests were acquired using the opto-digital microscope DSX500 by Japanese Olympus. DSX is a new line of opto-digital microscopes presented by Olympus at the beginning of 2012 .

\begin{tabular}{lc}
$\begin{array}{c}\text { Table 3: Conditions and parameters of the abrasive } \\
\text { water-jet processing for sample } 7 \text { and } 12\end{array}$ \\
\hline Type of abrasive & $\begin{array}{c}\text { Indian } \\
\text { Garnet }\end{array}$ \\
\hline Grit size & 80 \\
Pressure $p$, MPa & 350 \\
Water orifice diameter $d_{o}, \mathrm{~mm}$ & 0.14 \\
Abrasive mass flow rate $m_{a}, \mathrm{~g} / \mathrm{min}^{-1}$ & 400 \\
Focusing tube diameter $d_{f}, \mathrm{~mm}$ & 0.8 \\
Focusing tube length $I_{f}, \mathrm{~mm}$ & 78 \\
Angle of attack $\varphi{ }^{\circ}$ & 90 \\
Standoff distance $z, \mathrm{~mm}$ & 3 \\
Traverse speed $v, \mathrm{~mm} / \mathrm{min}^{-1}$ & 20 \\
Cutting direction, ${ }^{\circ}$ & 180 \\
\hline
\end{tabular}

This line currently includes three microscopes of different construction and designation: DSX500, DSX500i and DSX100 [23]. The opto-digital microscope DSX 500 [24], used in the experimental tests, was an instrument designed for carrying out observations with bright- and dark-field techniques. The main elements of the device were as follows:

- upright frame, providing a platform for the stage and the high-resolution optical head,

Nigerian Journal of Technology
- motorized stage for upright frame with the stroke $(x-y) \quad 100 \times 100 \mathrm{~mm}$ and load capacity of $3 \mathrm{~kg}$,

- high-resolution optical head using Peltier cooling 2.01 megapixels CCD detector with progressive scan,

- DSX dedicated objective lens XLMPLFLN10X and XLMPLFLN40X with magnifications $10 \times$ and $40 \times$ respectively,

- 23" Full HD color LCD monitor (Resolution: 1920(H)x1080(V)).

In order to control the instrument and perform the measurements, dedicated software DSX500 1.0. was used, while STREAM Motion Desktop 1.8 was used to process and analyze the images [25]. Both programs were provided by the microscope producer. The general view of the opto-digital microscope DSX500 is presented in Figure 2.

\section{Results and Discussion}

The following section presents the results of measurement of the surfaces of grinding wheels 1 $35 \times 20 \times 10 \quad$ CrA/F80J7V $(7+12)$ with shaped micro-discontinuities.

Figure 3 presents a vast panorama of surface fragments upon No. 7 sized $5.5 \times 3.7 \mathrm{~mm}$. This fragment was generated using the image mapping technique. It is now one of the standard programming procedures that makes it possible to create images of relatively large fragments of the registered surfaces through a skillful combination of numerous smaller images.

Vol. 33, No. 1, January 2014 


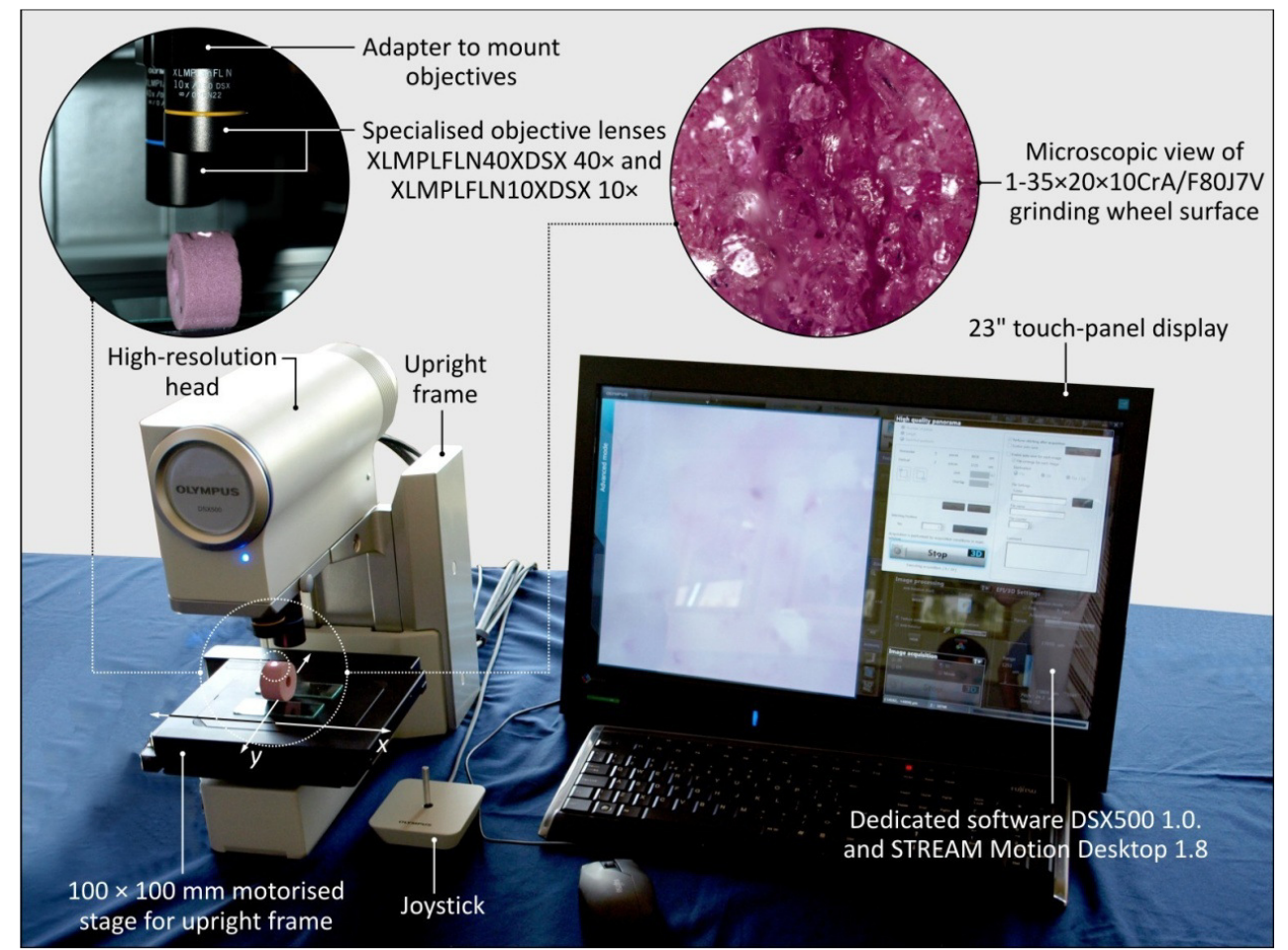

Figure. 2. General view of opto-digital microscope DSX500 produced by Olympus

In the discussed case the final image was created through a combination of 6 images sized $2 \times 2$ $\mathrm{mm}$, and their framing to the aforementioned dimensions. The high resolution of such an image $(3280 \times 2227$ pixels $)$ allowed for effective observation of the characteristic elements occurring on the grinding wheel surface such as: single PFA grains, ceramic bond with amorphous structure and free intergranular spaces.

Figure 4 presents the STREAM Motion Desktop 1.8 software window during determination of the surface profile of grinding wheel No. 7, with shaped micro-discontinuities. Its determinations made it possible to obtain information on the width and depth of these elements. In this case it was microdiscontinuity I (3.91 $\mathrm{mm}$ wide and 1.2 $\mathrm{mm}$ deep) and a small fragment of microdiscontinuity II ( $3.57 \mathrm{~mm}$ wide and $0.88 \mathrm{~mm}$ deep).

Figure 5 presents a 3D reconstruction of grinding wheel No. 12 for microdiscontinuity I and II. The input image was a surface fragment sized $2 \times 2$ $\mathrm{mm}$. Interactive 3D surface plot 2.1. plugin developed by K. U. Barthel (Internationale Medieninformatik, Berlin, Germany), operating in software Image J 1. 45, was used to generate the reconstruction. Application of spatial visualization is often a useful element, especially during visual analysis of the evaluated object.
Despite adoption of the agreed scale for axis $z$, the spatial presentation of the grinding wheel surface is and allows for much broader interpretation of its internal structure than in the case of typical two-dimensional images.

Figure 6 presents a comparison of values obtained using the opto-digital microscope DSX500 and the referential instrument. In this case it was an advanced 3D laser microscope LEXT OLS4000 by Olympus presented by Kapłonek and Nadolny [26]. Analyzing the obtained results, both in a visual manner and by following the values presented in the table, it can be observed that compatibility of results from both microscopes is very good. For grinding wheel No. 7 the differences, in relation to width, were contained within the range of $0.03 \mathrm{~mm}$ to $0.05 \mathrm{~mm}$; whilst for depth they were $0.01 \mathrm{~mm}$ to $0.02 \mathrm{~mm}$. Similar values were registered for grinding wheel No. 12 . When it comes to width, they ranged from $0.02 \mathrm{~mm}$ to $0.04 \mathrm{~mm}$. While for depth they ranged from $0.01 \mathrm{~mm}$ to $0.07 \mathrm{~mm}$. Taking into consideration the fact that instruments with different metrological parameters were used, the high quality of both measurement sets acquired, that only differ very slightly on the level of $\sim 1-6 \%$, needs to be stressed. 


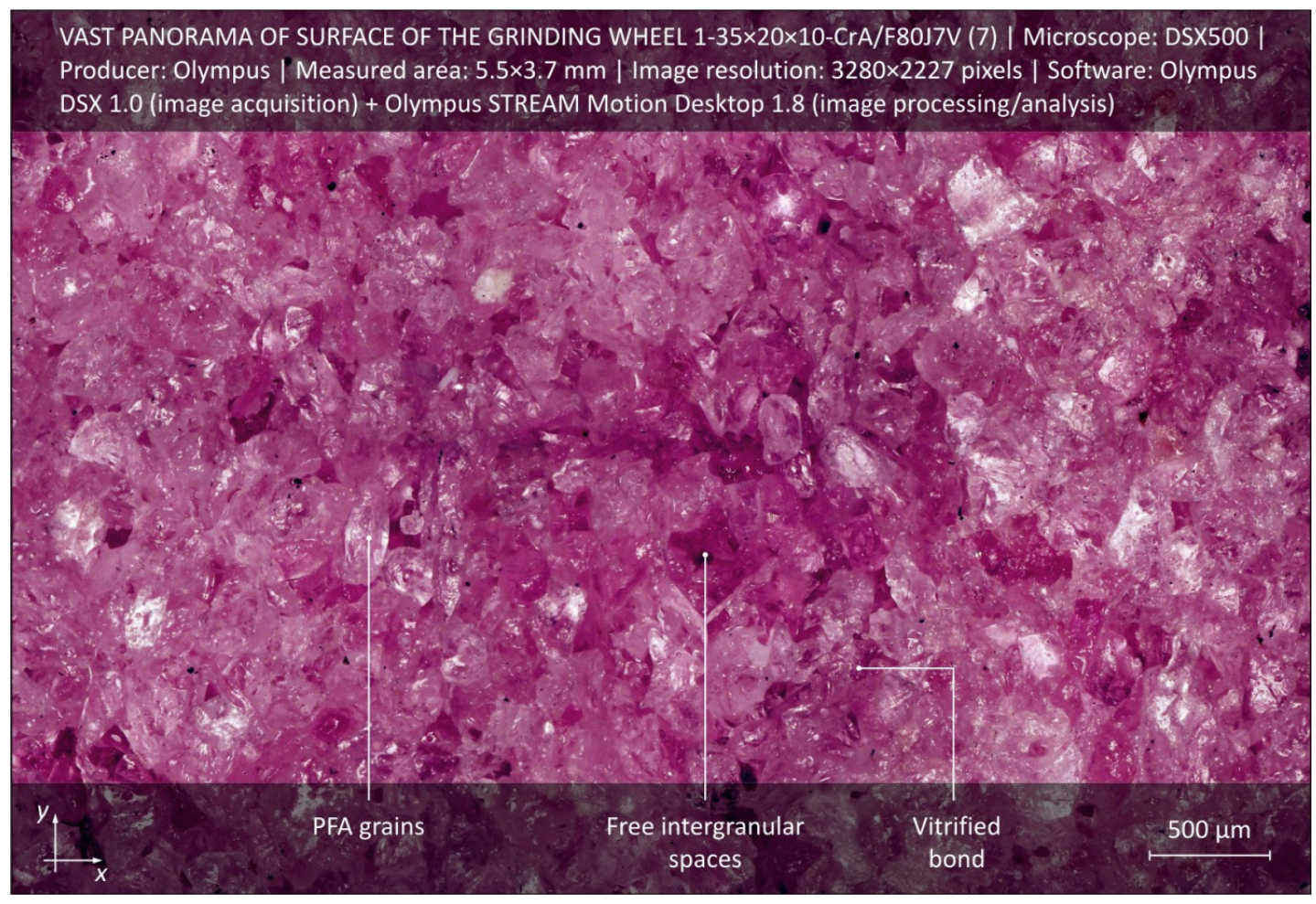

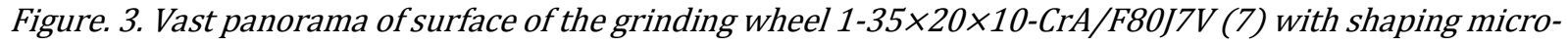
discontinuities

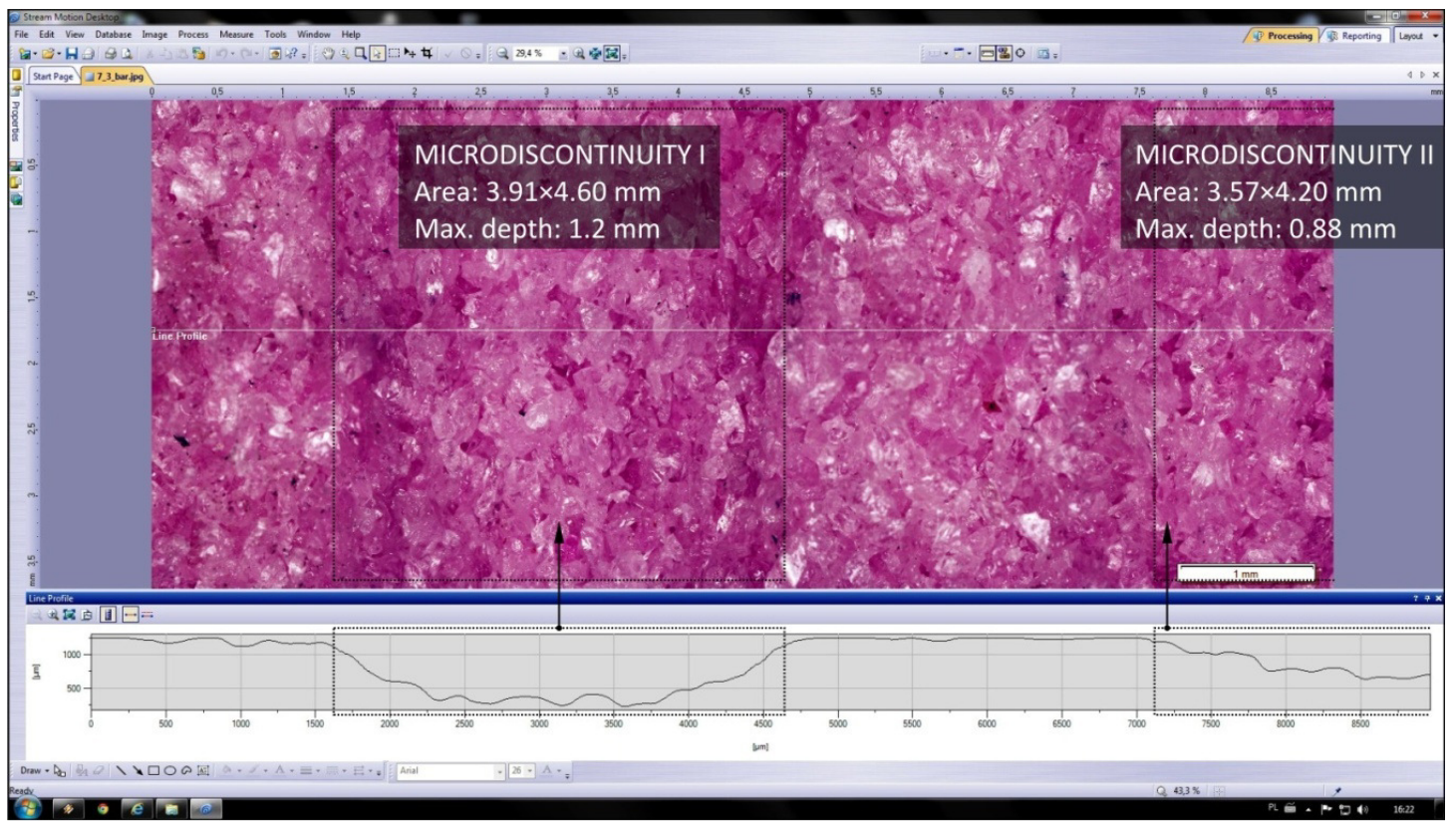

Figure. 4. Window of STREAM Motion Desktop 1.8 software produced by Olympus during line profile determining

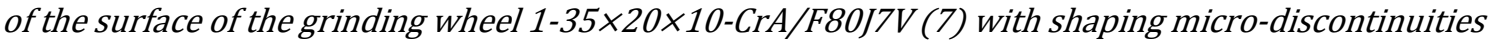




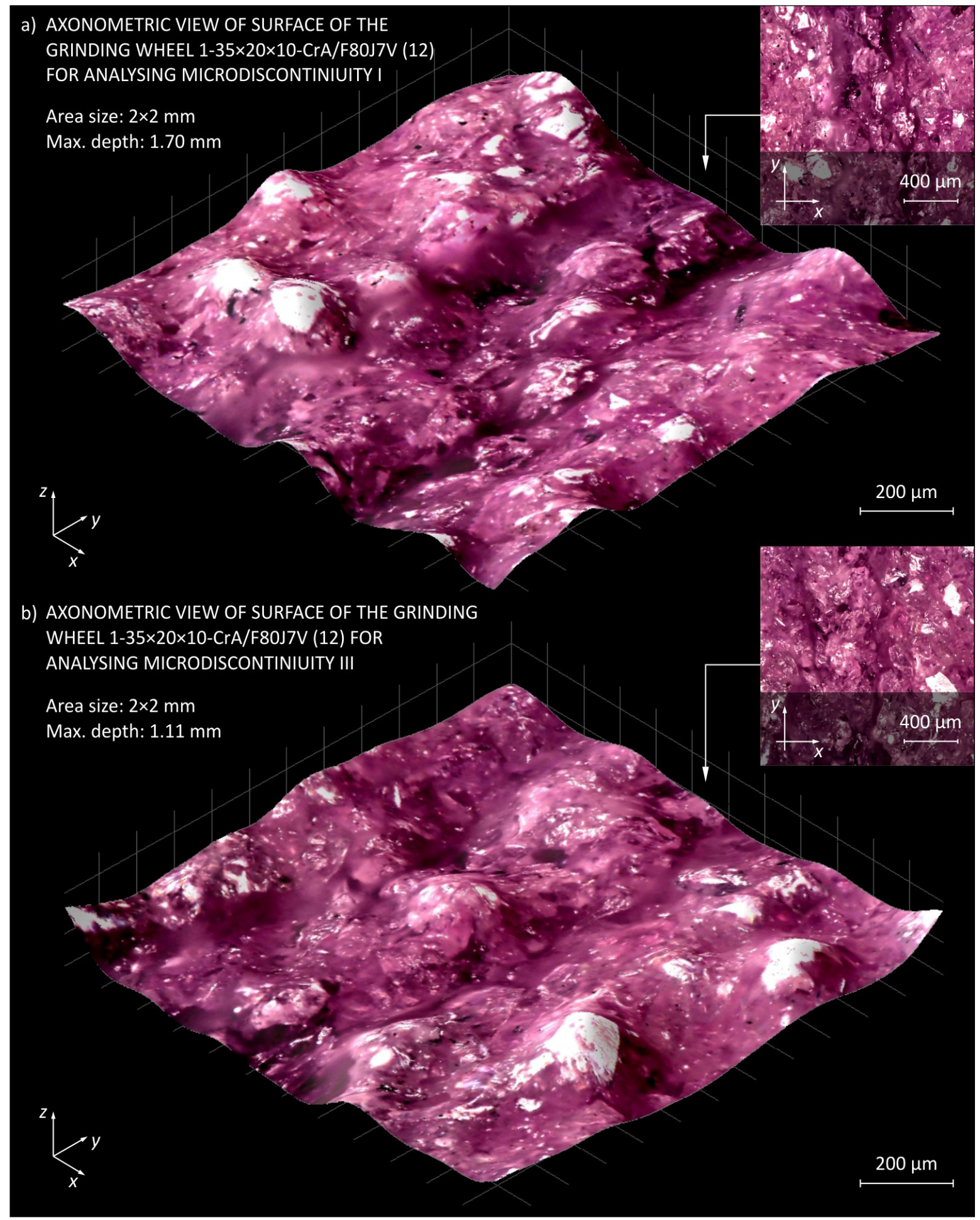

Figure. 5. 3D visualization of sample surface of the grinding wheel 1-35×20×10-CrA/F80J7V(12) with shaping: a) micro-discontinuity I; b) micro-discontiniuity III 
a)

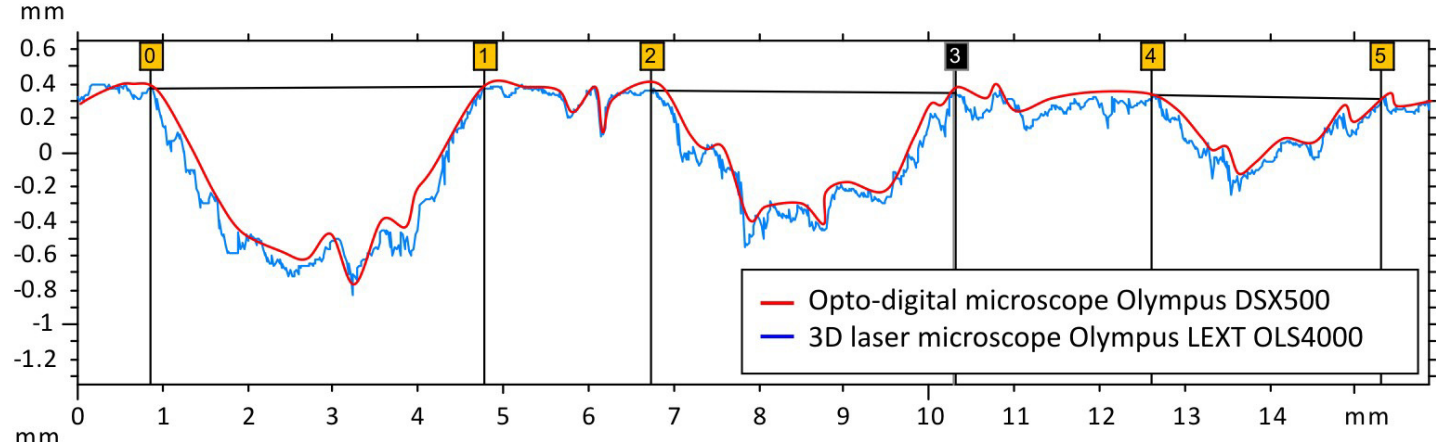

b)

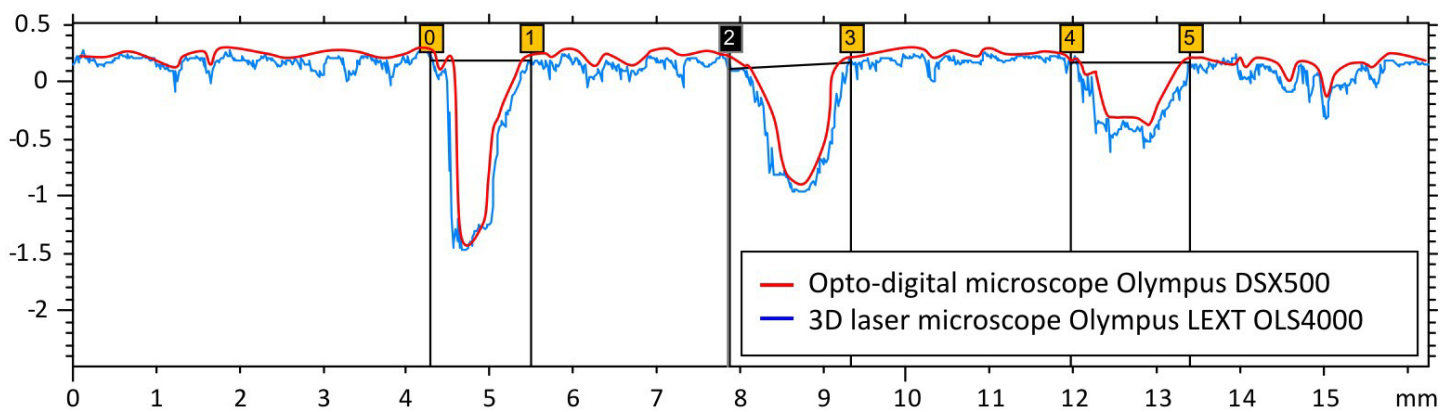

\begin{tabular}{|c|l|c|c|c|c|c|c|}
\hline \multirow{2}{*}{$\begin{array}{c}\text { Sample } \\
\text { No. }\end{array}$} & Microscope & \multicolumn{2}{|c|}{ Microdiscontiniuity I } & \multicolumn{2}{c|}{ Microdiscontiniuity II } & \multicolumn{2}{c|}{ Microdiscontiniuity III } \\
\cline { 3 - 8 } & $\begin{array}{c}\text { Width } \\
\mathrm{mm}\end{array}$ & $\begin{array}{c}\text { Depth } \\
\mathrm{mm}\end{array}$ & $\begin{array}{c}\text { Width } \\
\mathrm{mm}\end{array}$ & $\begin{array}{c}\text { Depth } \\
\mathrm{mm}\end{array}$ & $\begin{array}{c}\text { Width } \\
\mathrm{mm}\end{array}$ & $\begin{array}{c}\text { Depth } \\
\mathrm{mm}\end{array}$ \\
\hline \multirow{2}{*}{7} & OLS4000 & 3.91 & 1.20 & 3.57 & 0.88 & 2.68 & 0.56 \\
\cline { 2 - 8 } & DSX500 & 3.87 & 1.18 & 3.54 & 0.86 & 2.63 & 0.55 \\
\hline \multirow{2}{*}{12} & OLS4000 & 1.19 & 1.70 & 1.44 & 1.11 & 1.42 & 0.77 \\
\cline { 2 - 8 } & DSX500 & 1.17 & 1.69 & 1.41 & 1.04 & 1.38 & 0.73 \\
\hline
\end{tabular}

Figure. 6. Graphical comparison and table containing values obtained during geometric measurements of areas with micro-discontinuities upon the grinding wheel 1-35×20×10-CrA/F80J7V:a) 7; b) 14

\section{Conclusion}

The work presented highlights the new dynamically developing variation of light microscopy -so-called opto-digital microscopy. One of its applications concerning observation, registration and analysis of the GWAS, with technical designation $1-35 \times 20 \times 10-\mathrm{CrA} / \mathrm{F} 80 \mathrm{~J} 7 \mathrm{~V}$ and PFA grains containing shaped microdiscontinuities, was presented. The results of the experimental tests carried out can be summarized in the form of the following general conclusions:

1. Generally confirmed the potential offered by opto-digital microscopy technique in relation to the assessed surfaces.

2. The measurement possibility by using of DSX500 microscope by Olympus, were highly rated. Assessment of the examined grinding wheels surfaces was carried out with relatively short time with using of high-resolution measurements. Additionally the high accuracy and repeatability of the instrument was noted.

3. Considerable program support (STREAM Motion Desktop software) guaranteed the possibility for visual analysis of grinding wheel surface images at various magnifications. Also the correct determination of geometric values characterizing the analyzed objects (e.g. microdiscontinuities, PFA abrasive grains, free intergranular spaces) was confirmed.

4. For the DSX500 microscope, considerable result conformity was observed in comparison to the results obtained with 3D laser microscope OLS4000.

\section{Acknowledgement}

The authors would like to thank Mrs. Daniela Herman, D.Sc, Ph.D., from the Department of the Fundamentals of Material Science from the Institute of Technology and Education at Koszalin University of Technology, for preparing the grinding wheels for tests, Mr. Nikodem Szymański M.Sc, from Olympus Poland for the optical measurements of the grinding wheels and substantive discussions focusing on important aspects of modern opto-digital microscopy as well as Mr. Robert Tomkowski, M.Sc., B.Sc., from the Laboratory of Micro- and Nanoengineering at 
Koszalin University of Technology, for the comparative measurements of the samples tested using a 3D laser microscope Olympus LEXT OLS4000.

\section{References}

[1] Malkin, S. and Guo, C. Grinding Technology: Theory and Application of Machining with Abrasives, Industrial Press, New York, 2008.

[2] Chen, J., Shen, J., Huang, H. and Xu, X. "Grinding Characteristics in High Speed Grinding of Engineering Ceramics with Brazed Diamond Wheels", Journal of Materials Processing Technology, Vol. 210, No. 6-7, 2010, pp 899-906.

[3] Stephenson, D. J., Jin, T. and Corbett, J. "High Efficiency Deep Grinding of a Low Alloy Steel with Plated CBN Wheels", CIRP Annals Manufacturing Technology, Vol. 51, No. 1, 2002, pp 241-244.

[4] Shimizu, J., Zhou, L. B. and Eda, H. "Simulation and Experimental Analysis of Super High-Speed Grinding of Ductile Material", Journal of Materials Processing Technology, Vol. 29, No. 1-3, 2002, pp 19-24.

[5] Odior, A. O. and Oyawale, F. A. "Performance Evaluation of Abrasive Grinding Wheel Formulated from Locally Sourced Materials", Nigerian Journal of Technology, Vol. 32, No. 2, 2013, pp 318-324.

[6] Valíček, J., Hloch, S. and Kozak D. "Surface Geometric Parameters Proposal for the Advanced Control of Abrasive Waterjet Technology ", The International Journal of Advanced Manufacturing Technology, Vol. 41, No. 3-4, 2009, pp 323-328.

[7] Jackson, M. J., Davim, J. P. Machining with Abrasives. Springer, New York, 2010.

[8] Marinescu, I. D., Rowe, W. B., Dimitrov, B. and Inasaki, I. Tribology of abrasive machining processes. William Andrew, Norwich, 2004.

[9] Klocke, F. Manufacturing Processes 2: Grinding, Honing, Lapping. Springler-Verlag, Berlin, 2009.

[10] Xu, X., Yu Y. and Huang H., "Mechanisms of Abrasive Wear in the Grinding of Titanium (TC4) and Nickel (K417) Alloys", Wear, Vol. 255, No. 712, 2003, pp 1421-1426.

[11] Jackson, M. J. and Mills, B., "Microscale Wear of Vitrified Abrasive Materials", Journal of Materials Science, Vol. 39, No. 6, 2004, pp 2131-2143.

[12] Kapłonek, W., Łukianowicz, C. and Nadolny, K. "Methodology of the Assessment of the Abrasive Tool's Active Surface using Laser Scatterometry",
Transactions of the Canadian Society for Mechanical Engineering, Vol. 36, No. 1, 2012, pp 49-66.

[13] Kapłonek, W. and Nadolny, K. "Review of the Advanced Microscopy Techniques used for Diagnostics of Grinding Wheels with Ceramic Bond", Journal of Machine Engineering, Vol. 12, No. 4, 2012, pp 81-98.

[14] Nadolny, K. "Microdiscontinuities of the Grinding Wheel and Their Effects on its Durability During Internal Cylindrical Grinding", Machining Science and Technology, Vol. 17, No. 1, 2013, pp 74-92.

[15] Inoué, S. Video Microscopy, Plenum Press, New York, 1986.

[16] Inoué, S. "Progress in Video Microscopy", Cell Motility and the Cytoskeleton, Vol. 10, No. 1-2, 1988, pp 13-17.

[17] Jarvis, L. R. "Microcomputer Video Image Analysis", Journal of Microscopy, Vol. 150, No. 2. 1988, pp 83-97.

[18] Inoué, S. and Spring, K. R. Video Microscopy: The Fundamentals (2nd Edition), Plenum Press, New York, 1997.

[19] Sluder, G. and Wolf, D. E. (Eds.) Video Microscopy. Academic Press, San Diego, 1998.

[20] Wayne, R. O. Light and Video Microscopy. Academic Press, Burlington, 2009.

[21] Sluder, G. and Wolf, D. E. (Eds.) Digital Microscopy (4th Edition), Methods in Cell Biology series, Vol. 114, Academic Press, New York, 2013.

[22] Gualtieri, P., Barsanti, L., Coltelli, P. and Evangelista, V. Optical Digital Microscopy, CRC Press, New York, 2010.

[23] Olympus Corporation "Opto-digital Microscopes DSX series" http://www.olympusims.com/en/microscope/dsx/, Accessed on August 2, 2013.

[24] Olympus Corporation "Opto-Digital Microscope DSX500" http://www.lri.se/pdf/olympus/DSX500 en 3.p df, Accessed on August 2, 2013.

[25] Olympus Corporation "Image Analysis Software OLYMPUS Stream for Material Science Microscopes" http://www.lri.se/pdf/olympus/Olympus Strea m Software.pdf, Accessed on August 2, 2013.

[26] Kapłonek, W. and Nadolny, K. "Advanced 3D Laser Microscopy for Measurements and Analysis of Vitrified Bonded Abrasive Tools", Journal of Engineering Science \& Technology, Vol. 7, No. 6, 2012, pp 661-732. 